\title{
Characterisation of extreme winter precipitation in Mediterranean coastal sites and associated anomalous atmospheric circulation patterns
}

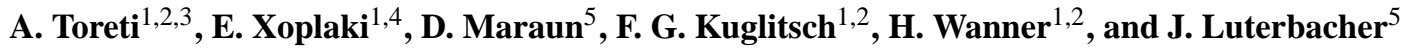 \\ ${ }^{1}$ Institute of Geography, Climatology and Meteorology, University of Bern, Bern, Switzerland \\ ${ }^{2}$ Oeschger Centre for Climate Change Research (OCCR), University of Bern, Bern, Switzerland \\ ${ }^{3}$ Istituto Superiore per la Protezione e la Ricerca Ambientale (ISPRA), Rome, Italy \\ ${ }^{4}$ The Cyprus Institute, EEWRC, Nicosia, Cyprus \\ ${ }^{5}$ Department of Geography, Climatology, Climate Dynamics and Climate Change, Justus-Liebig University of Giessen, \\ Giessen, Germany
}

Received: 31 January 2010 - Revised: 17 April 2010 - Accepted: 24 April 2010 - Published: 20 May 2010

\begin{abstract}
We present an analysis of daily extreme precipitation events for the extended winter season (OctoberMarch) at 20 Mediterranean coastal sites covering the period 1950-2006. The heavy tailed behaviour of precipitation extremes and estimated return levels, including associated uncertainties, are derived applying a procedure based on the Generalized Pareto Distribution, in combination with recently developed methods. Precipitation extremes have an important contribution to make seasonal totals (approximately $60 \%$ for all series). Three stations (one in the western Mediterranean and the others in the eastern basin) have a 5-year return level above $100 \mathrm{~mm}$, while the lowest value (estimated for two Italian series) is equal to $58 \mathrm{~mm}$. As for the 50-year return level, an Italian station (Genoa) has the highest value of $264 \mathrm{~mm}$, while the other values range from 82 to $200 \mathrm{~mm}$. Furthermore, six series (from stations located in France, Italy, Greece, and Cyprus) show a significant negative tendency in the probability of observing an extreme event. The relationship between extreme precipitation events and the large scale atmospheric circulation at the upper, mid and low troposphere is investigated by using NCEP/NCAR reanalysis data. A 2-step classification procedure identifies three significant anomaly patterns both for the western-central and eastern part of the Mediterranean basin. In the western Mediterranean, the anomalous southwesterly surface to mid-tropospheric flow is connected with enhanced
\end{abstract}

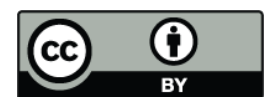

Correspondence to: A. Toreti (toreti@giub.unibe.ch) moisture transport from the Atlantic. During $\geq 5$-year return level events, the subtropical jet stream axis is aligned with the African coastline and interacts with the eddy-driven jet stream. This is connected with enhanced large scale ascending motions, instability and leads to the development of severe precipitation events. For the eastern Mediterranean extreme precipitation events, the identified anomaly patterns suggest warm air advection connected with anomalous ascent motions and an increase of the low- to mid-tropospheric moisture. Furthermore, the jet stream position (during $\geq 5$ year return level events) supports the eastern basin being in a divergence area, where ascent motions are favoured. Our results contribute to an improved understanding of daily precipitation extremes in the cold season and associated large scale atmospheric features.

\section{Introduction}

Extreme precipitation events have a profound impact on society due to the growth of human vulnerability (Trenberth et al., 2007). Increasing population densities in high-risk areas and limited action plans by local governments lead to a rise of the destructive potential of weather and climate extremes. Many European countries are experiencing a sprawl of urban areas, especially towards the Mediterranean coasts (EEA, 2006). Moreover, a growth of residential and industrial areas has been observed in many European countries over the period $1990-2000$ (>5\% and $>10 \%$, respectively; ESPON, 2006).

Published by Copernicus Publications on behalf of the European Geosciences Union. 
Between 1950 and October 2009, 395 severe flood and storm events were reported by EM-DAT (2009) for 19 Mediterranean countries. EM-DAT (2009) reports only the most severe events, while the combined criteria for an extreme event are over nine fatalities and 99 affected, declaration of the emergency state and a call for international assistance. The estimated cost of damage for these severe events was approximately 64 billion US dollars, together with 9904 fatalities and about 12 million injured, homeless or people that required immediate assistance (EM-DAT, 2009).

Monthly, seasonal and annual series of precipitation totals were analysed for Mediterranean countries in several studies (e.g., Brunetti et al., 2006; De Luis et al., 2009; Toreti et al., 2009; Türkes et al., 2009; del Río et al., 2010). The behaviour of the Mediterranean winter precipitation during the 20th century does not show a clear spatial pattern (in terms of trend), but differences due to the influence of local and regional factors as well (e.g., González-Hidalgo et al., 2001; Xoplaki et al., 2004; Foley et al., 2005). The analysis of extreme precipitation events is a complex task and it was often studied by using indices (e.g., Frich et al., 2002; Klein Tank and Können, 2003; Haylock and Goodess, 2004; Kostopoulou and Jones, 2005; Zhang et al., 2005; Gallego et al., 2006; Moberg et al., 2006; Norrant and Douguédroit, 2006; Brunet et al., 2007; Rodrigo and Trigo, 2007; Costa and Soares, 2009; Kioutsioukis et al., 2010; López-Moreno et al., 2010). Alpert et al. (2002) analysed the contribution to the total annual rainfall of six precipitation categories from light (with a daily amount between 0 and $4 \mathrm{~mm}$ ) to torrential (greater than $128 \mathrm{~mm} /$ day) at different stations in the Mediterranean. For the higher categories (heavy to torrential), increasing trends were found in Spain and Italy; whereas, for the central categories, highly significant decreasing trends were detected. No significant changes were identified in Israel and Cyprus. Kostopoulou and Jones (2005) reported positive trends in the number of days with daily precipitation above $10 \mathrm{~mm}$ for the series recorded in Italy and significant negative trend in the eastern part of the Mediterranean (mainly in the western part of Greece). In the Middle East, weak non-significant trends in precipitation indices and a lack of spatial coherence were found by Zhang et al. (2005). In the western part of the Mediterranean basin, Moberg et al. (2006) showed many non-significant trends for winter series of Prec $90 p$ and Prec $98 p$ (90th, 98th, percentile of daily precipitation obtained using all days in a season). Norrant and Douguédroit (2006) analysed the behaviour of monthly and daily precipitation series collected in the Mediterranean area. They found a significant decrease in the winter (December-February; 1950-2000) number of days with daily precipitation above $10 \mathrm{~mm}$ in the Italian and Gulf of Genoa subregions ( -3 days/50-year) and in the eastern part of the Mediterranean ( -4 days/50-year). Furthermore, they found a significant decrease in the winter sum of daily precipitation above $10 \mathrm{~mm}$ in the Italian, Greek and eastern Mediterranean subregions (-74.2, -74.2, and $-115.1 \mathrm{~mm} / 50$-year, respectively). At the Greek stations, the sum of daily precipitation greater than the 95th percentile had a positive trend equal to $34.6 \mathrm{~mm} / 50$-year (Norrant and Douguédroit, 2006). As for Greece, Kioutsioukis et al. (2010) showed a decreasing trend in the annual number of days with daily precipitation above $10 \mathrm{~mm}$, but no significant changes in the annual precipitation fraction due to events above the 95th percentile. Regarding the Iberian Peninsula, non-significant changes in extreme precipitation indices were detected in the majority of the analysed series (Gallego et al., 2006; Brunet et al., 2007; Costa and Soares, 2009). However, López-Moreno et al. (2010) reported a decreasing trend in the annual number of days with daily precipitation above the 90th percentile for $49 \%$ of the analysed series in the northeastern part of the Iberian Peninsula.

Indices, based on percentiles or fixed thresholds (as in the previous cited studies), have been extensively applied. Since they do not provide an exhaustive description of the extreme precipitation behaviour, some studies have applied techniques derived in the context of Extreme Value Theory (EVT) (e.g., Coles and Pericchi, 2003; Yiou and Nogaj, 2004; Vrac and Naveau, 2007; Yiou et al., 2008; Maraun et al., 2009; Rust et al., 2009). The application of EVT to precipitation data requires careful treatment. EVT analysis can be performed in different ways, for example, by using only annual or monthly maxima (block-maxima approach) or all values above a threshold (peaks over threshold approach). The latter approach, in general, makes more efficient use of the data (e.g., Coles, 2001; IPCC, 2002). Therefore, in this analysis the peaks over threshold approach is followed, improving the available procedures (as explained in Sect. 3).

Large scale atmospheric circulation (in association with regional and local factors) is important to determine precipitation anomalies at different time scales, from sub-daily to seasonal. Studies linked monthly to seasonal station or gridded precipitation data with large scale atmospheric circulation anomalies or derived circulation indices (e.g., Zorita et al., 1992; Corte-Real et al., 1995; Türkes, 1998; Quadrelli et al., 2001; Krichak et al., 2002; Xoplaki, 2002; Dünkeloh and Jacobeit, 2003; Xoplaki et al., 2004; Valero et al., 2004; Ziv et al., 2006). So far, only a few studies investigated largescale circulation and extreme precipitation events at a daily scale (e.g., Tolika et al., 2007; Yiou et al., 2008; Maraun et al., 2010a,b).

In this contribution, we use a dataset of 20 daily extended winter (October-March) precipitation series collected in the Mediterranean and covering the period 1950-2006. The application of extreme distributions to precipitation series has many complex steps; therefore, a procedure based on the Generalized Pareto Distribution (GPD) and combining new methods developed in the field of EVT, is proposed. It has technical advantages with respect to the objective choice of the threshold parameter (see Sect. 3 for a formal definition), the tendency of precipitation to occur in clusters and the GPD-parameters estimation. In order to obtain a 
description of the troposphere circulation dynamics, an analysis of atmospheric variables is also performed. Geopotential height at $500 \mathrm{hPa}$ and Sea Level Pressure anomalies (see next section) are analysed, applying a new 2-step classification procedure (see Sect. 3 for details) that identifies and characterises the optimal number of clusters for a large amount of data. Finally, it is well known that jet streams play an important role in the atmosphere, for example, they represent a critical parameter for the behaviour of planetary waves (Ruti et al., 2006). The entrance and exit areas of a jet stream contribute to determine the distribution of upper-tropospheric divergence and relative vorticity (Barry and Carleton, 2001); moreover, jet streams are linked to mid-latitude storm tracks and stratosphere-troposphere exchange (Shapiro, 1980; Keyser and Shapiro, 1986; Eisele et al., 1999; Strong and Davis, 2007). Therefore, a description of the jet stream features during extreme precipitation events is also provided.

In Sect. 2, the available data are described. Section 3 provides an explanation of applied methods and finally, results are shown in Sect. 4; conclusions are provided in the last section.

\section{Data}

Daily precipitation series (characterised by completeness and temporal continuity) from 20 coastal stations across the Mediterranean are selected among the entire dataset collected within the EU-FP6 project CIRCE (Climate Change and Impact Research: the Mediterranean Environment). Figure 1 (and Table 1) shows the location of the stations. The North African coast is not represented in the dataset. The temporal coverage of the selected data is 1950-2006, with six series that end in 2001. The quality of data affects the climate analysis, therefore, all the series are in a first step quality controlled and checked for homogeneity. An advanced correction method, specifically developed for daily precipitation time series, does not exist yet. In our approach, we reject series characterised by more than two break points (i.e., inhomogeneities). The identification of break points is carried out applying a new method developed by Toreti et al. (2010) and the method of Caussinus and Mestre (2004). The former break detection method is based on a Genetic Algorithm and Hidden Markov Models and has good performance with multiple break points (for a complete description, the reader is referred to Toreti et al., 2010). The daily series of the station located in Emilia-Romagna (Italy) was also quality controlled (including break-point detection) by Pavan et al. (2008). The extreme characterisation (defined in the following section) is done for the extended winter season (October-March). For the identification of the atmospheric anomaly patterns associated with the extreme events (see Sect. 3), daily NCEP/NCAR reanalysis of the mid-tropospheric geopotential height at $500 \mathrm{hPa}$ (Z500), Sea
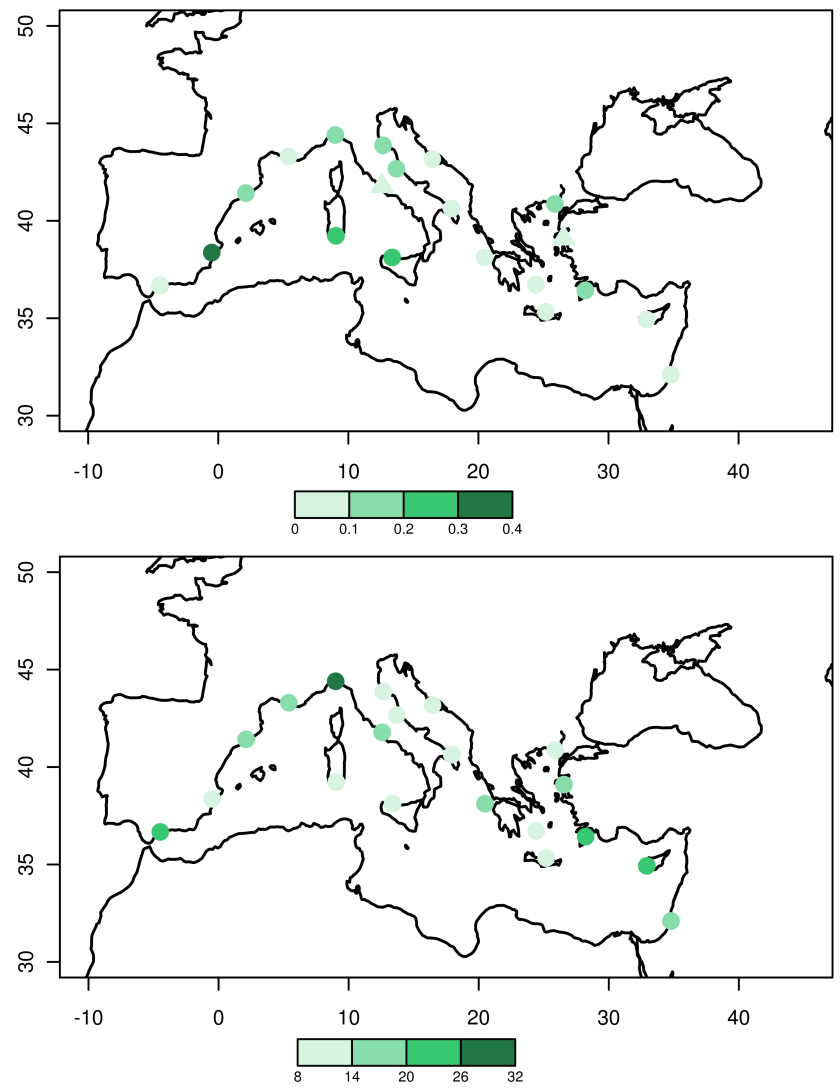

Fig. 1. Geographical position of the 20 stations. Colours are associated with the shape (upper panel) and scale (lower panel) parameters of the GPD estimated for each series. In the shape plot, triangles denote a negative value.

Level Pressure (SLP) and wind intensity of the two components, $u$ and $v$, at $250 \mathrm{hPa}$ are used (Kalnay et al., 1996; Kistler et al., 2001). The spatial window covering the area from $25^{\circ} \mathrm{N}$ to $65^{\circ} \mathrm{N}$ and $35^{\circ} \mathrm{W}$ to $52^{\circ} \mathrm{E}$ is selected. In order to obtain anomalies, the mean seasonal cycle is removed from the atmospheric gridded data (Z500 and SLP; using the period 1950-2006). The mean of each grid point for each day of the year is calculated over the whole period. The obtained seasonal cycles are then smoothed using a penalized spline (e.g., Krivobokova and Kauermann, 2007) and removed from the original data.

\section{Methods}

\section{1 dePOT model}

The available methods for the EVT analysis of the extremes are based on the so-called Generalized Extreme Value (GEV) distribution and the Generalized Pareto Distribution-GPD (for an overview, see Coles, 2001). GEV is usually applied with a block-maxima approach, i.e. the maximum of a user-defined block (e.g., a month, a season or a year). It is important to underline that the whole extreme value 
Table 1. Name, country and geographical coordinates (latitude and longitude) of the 20 stations. 5 and 50-year return levels and associated uncertainties, values in $\mathrm{mm}$.

\begin{tabular}{lllccccc}
\hline Station & Country & Lat & Lon & 5-year & $\begin{array}{c}\text { 5-year } \\
\text { std error }\end{array}$ & 50-year & $\begin{array}{c}\text { 50-year } \\
\text { std error }\end{array}$ \\
\hline Alexandroupoli & Greece & 40.87 & 25.88 & 74 & 11 & 134 & 39 \\
Alicante & Spain & 38.37 & -0.5 & 70 & 21 & 200 & 127 \\
Amiantos & Cyprus & 34.93 & 32.92 & 115 & 13 & 183 & 37 \\
Argostoli & Greece & 38.12 & 20.48 & 90 & 10 & 134 & 26 \\
Barcelona & Spain & 41.42 & 2.12 & 77 & 13 & 153 & 56 \\
Brindisi & Italy & 40.63 & 17.93 & 69 & 9 & 113 & 28 \\
Cagliari & Italy & 39.23 & 9.05 & 58 & 10 & 119 & 38 \\
Genoa & Italy & 44.4 & 9 & 150 & 22 & 264 & 76 \\
Heraklion & Greece & 35.33 & 25.18 & 63 & 7 & 97 & 19 \\
Hvar & Croatia & 43.17 & 16.45 & 66 & 10 & 110 & 31 \\
Malaga & Spain & 36.67 & -4.48 & 91 & 11 & 141 & 30 \\
Marseille & France & 43.3 & 5.4 & 73 & 11 & 127 & 35 \\
Milos & Greece & 36.73 & 24.42 & 62 & 8 & 99 & 24 \\
Mytilene & Greece & 39.1 & 26.55 & 83 & 8 & 120 & 21 \\
Palermo & Italy & 38.12 & 13.37 & 58 & 9 & 116 & 35 \\
Rhodes & Greece & 36.43 & 28.22 & 114 & 16 & 195 & 51 \\
Rimini & Italy & 43.87 & 12.67 & 67 & 9 & 113 & 30 \\
Rome & Italy & 41.78 & 12.58 & 60 & 6 & 82 & 13 \\
Tel Aviv & Israel & 32.1 & 34.78 & 80 & 9 & 125 & 27 \\
Teramo & Italy & 42.67 & 13.7 & 68 & 9 & 121 & 32 \\
\hline
\end{tabular}

analysis is based on the Extremal Types Theorem ETT (e.g., Leadbetter et al., 1983). Let $X_{1}, X_{2}, \ldots$ be a sequence of independent random variables with a common distribution $F$ and $M_{n}$ denotes the maximum of $\left(X_{1}, \ldots, X_{n}\right)$. ETT states that if for some constants $a_{n}>0$ and $b_{n}, P\left\{a_{n}\left(M_{n}-b_{n}\right) \leq x\right\}$ converges to a non-degenerate distribution $G$, then this distribution is one of the three types characterising the GEV family. In order to use the information from the entire daily series, we implemented a procedure based on the GPD, called declustered Peak Over Threshold (dePOT; Davison and Smith, 1990). GPD arises as an approximation of the Xexceedances (over a defined threshold) distribution, i.e., with the same assumption of the ETT for a large enough threshold $u$ the distribution of $X-u$ conditional on $X>u$ belongs to the GPD family (Pickands, 1975):

$H(y)=1-\left(1+\frac{\xi y}{\sigma}\right)^{-1 / \xi}$,

where $\xi$ and $\sigma$ are the shape and the scale parameter, respectively. The $\xi$ parameter identifies the distribution type, i.e., for $\xi<0$ the distribution has an upper bound, if $\xi>0$ there is not an upper limit and if $\xi=0$ the distribution is exponential.

\subsection{Model inference}

There are several available methods for the estimation of the parameters (see for an overview of the early developed methods Castillo and Hadi, 1997), such as: maximum likelihood (e.g., Coles, 2001), probability weighted moments (Hosking and Wallis, 1987) and medians estimator (Peng and Welsh, 2002). In this context, Juárez and Schucany (2004) developed a robust technique called Minimum Density Power Divergence Estimator MDPDE (see Appendix A). The MDPDE is controlled by a constant $\alpha$ (see Appendix A). The estimator is applied to our series with $\alpha=0.1$, thus, maintaining a good asymptotic efficiency.

The choice of the threshold $u$ should guarantee the convergence and a good number of exceedances for the distribution estimation. The most often applied method is the socalled Mean Residual Life Plot (e.g., Coles, 2001), though it has a high degree of subjectivity. We replace the Mean Residual Life Plot approach with a Goodness-of-fit approach (Choulakian and Stephens, 2001). Thus, we test the goodness of the estimated GPD $(\hat{F})$ as a function of $u$ using the Cramér-von Mises statistic $W^{2}$ and the Anderson-Darling statistic $A^{2}$. Let us assume that $x_{1}, \ldots, x_{n}$ is a sample from $\hat{F}$, the calculation of $z_{i}=\hat{F}\left(x_{(i)}\right)\left(\right.$ where $\left.x_{(1)} \leq x_{(2)} \leq \ldots \leq x_{(n)}\right)$ lead to:

$W^{2}=\sum_{i=1}^{n}\left\{z_{i}-(2 i-1) /(2 n)\right\}^{2}+1 /(12 n)$

$A^{2}=-n-\left((1 / n) \sum_{1}^{n}(2 i-1)\left[\log \left(z_{i}\right)+\log \left(1-z_{n+1-i}\right)\right]\right)$.

Under the null hypothesis the sample stems from a GPD. Therefore, starting with $u$ equal to the 90th percentile, the 
threshold is raised until the p-values, associated with the two statistics, are greater than 0.1. At first, we have supposed that $X_{1}, X_{2}, \ldots$ are independent, however, daily precipitation series do not satisfy this condition. Therefore, the approach described above needs to be modified. First, it is essential to note that ETT is still valid for dependent data replacing the independence condition with the so-called $D\left(u_{n}\right)$ condition. In short, a stationary series satisfies the $D\left(u_{n}\right)$ condition if two extreme events occurring at times $t_{i}$ and $t_{j}$ (far enough) are independent (for details see Leadbetter et al., 1983). Then, we introduce the concept of extremal index $\theta$ (Leadbetter et al., 1983): $\left\{X_{n}\right\}_{n \geq 1}$ has $\theta$ (in $[0,1])$ if for each $\tau>0$ there is a sequence $\left\{u_{n}\right\}_{n \geq 1}$ such that: $n\left(1-F\left(u_{n}\right)\right) \rightarrow \tau$ and $P\left(M_{n} \leq u_{n}\right) \rightarrow \exp (-\theta \tau)$. It means that (if $\theta<1$ ) the exceedances tend to cluster and the clusters may be considered independent. Furthermore, $\theta$ can be interpreted as the reciprocal of the mean cluster size (Leadbetter et al., 1983). The most often used method for cluster identification is runs-declustering (e.g., Coles, 2001). However, Ferro and Segers (2003) developed an objective procedure for that task, so we applied it. They proposed an estimator $\hat{\theta}$ of the extremal index and the following procedure for declustering. Let us assume that $S_{1}<\ldots<S_{N}$ are the exceendance times of our process with interexceedance times $T_{i}=S_{i+1}-S_{i}, i=1, \ldots, N-1$. Let $T_{(C)}$ be the $C$-th largest interexceedance time $(C=\lfloor\hat{\theta} N\rfloor+1), T_{i_{j}}$ be the $j$-th interexceedance time greater than $T_{(C)}, i_{0}=0$ and $i_{C}=N$. Then the set $\left\{\mathcal{T}_{j}\right\}_{j=1, \ldots, C}$, where $\mathcal{T}_{j}=\left\{T_{i_{j-1}+1}, \ldots, T_{i_{j}-1}\right\}$, is made up of independent intracluster times with an associated set of exceedance times $\mathcal{S}_{j}=\left\{S_{i_{j-1}+1}, \ldots, S_{i_{j}}\right\}$.

The application of an extreme model, such as dePOT, gives the possibility of estimating the so-called return level $z_{\mathrm{R}}$, i.e., the level that is expected to be exceeded on average once every R-years (Coles, 2001). It is estimated with the following equation (derived from Eq. 1):

$z_{\mathrm{R}}=u+\hat{\sigma} \hat{\xi}^{-1}\left[\left(\mathrm{R} \zeta_{u} \hat{\theta}\right)^{\hat{\xi}}-1\right]$,

where, $\zeta_{u}$ is the probability of exceeding the threshold (i.e., the intensity of the assumed Poisson process describing the occurrence of exceedances; Davison and Smith, 1990). Assuming stationarity, $\zeta_{u}$ can be replaced by $n_{u} / n$, i.e., the number of exceedances divided by the number of observations. The errors associated with the return levels are calculated using the estimated variance-covariance matrix (see Appendix A) and applying the delta method (Shao, 2003).

\subsection{Atmospheric patterns}

Gridded anomalies of Z500 and SLP during extreme days (i.e., days with precipitation above the selected threshold, as explained in the previous subsections), rainy days below the identified threshold (i.e., the threshold of the extreme model) and dry days are extracted. The last two classes are used for the assessment of the significance associated with anomalies of the first class. The three precipitation classes are separately analysed with the following procedure. The corresponding maps are classified using a 2-level clustering algorithm (Vesanto and Alhoniemi, 2000). During the first phase the entire set (of cardinality $N$ ) undergoes a procedure for the identification of protoclusters. This step is performed applying the Self-Organizing Map (SOM) method (Kohonen, 2001). SOM can be defined (Kohonen, 2001) as an iterative nonlinear projection of a probability density function of a vector in $\mathfrak{R}^{n}$ onto a 2-dimensional display. SOM compares the input vector $\boldsymbol{x}$ with a set of nodes $\boldsymbol{m}_{i}(i=1, \ldots, d)$ and the best matching node $\boldsymbol{m}_{c}$ is determined by minimizing $\left\|\boldsymbol{x}-\boldsymbol{m}_{i}\right\|$. The nodes are updated according to:

$\boldsymbol{m}_{i}^{t+1}=\boldsymbol{m}_{i}^{t}+h_{c i}\left[\boldsymbol{m}-\boldsymbol{m}_{i}^{t}\right]$,

where $t$ denotes the time iteration step, and $h_{c i}=$ $\alpha(t) \exp \left\{-\left(2 \sigma^{2}(t)\right)^{-1}\left\|\boldsymbol{r}_{c}-\boldsymbol{r}_{i}\right\|^{2}\right\} . \alpha$ and $\sigma$ are two parameters named learning rate and radius factor, respectively; while $\boldsymbol{r}_{c}$ and $\boldsymbol{r}_{i}$ (belonging to $\Re^{2}$ ) are the positions of nodes $c$ and $i$. The protoclusters undergo a modified k-means clustering procedure (Hartigan and Wong, 1979), in order to overcome the well-known drawbacks of the method linked to the random initialization of centroids. In fact, following Krishna and Narasimha Murty (1999) a Genetic k-means algorithm (GK) is applied. It is a Genetic Algorithm (Holland, 1992) with a k-means operator for improving the convergence. In brief, denoting the number of protoclusters with $n_{\mathrm{p}}$, it compares vectors $\boldsymbol{v}$ of $\mathrm{n}_{\mathrm{p}}$-dimension iteratively; components of $\boldsymbol{v}$ (i.e., elements to be clusterized) take values in $\{1, \ldots, K\}$ (where $K$ is the final number of clusters), i.e., $v_{i}=j$ if $\boldsymbol{v}_{i}$ belongs to the $j$-th cluster. The Genetic component creates a population (random at the beginning) of vectors and evaluates this population by using a fitness function, based on the Total Within Cluster Variation:

$\mathrm{TWCV}=\sum_{k=1}^{K} \sum_{\boldsymbol{x} \in k}\left\|\boldsymbol{x}-\boldsymbol{c}_{k}\right\|$,

where $\boldsymbol{x} \in k$ means $\boldsymbol{x}$ belongs to the $k$-th cluster. The population is evaluated applying the so-called tournament selection technique (Blickle and Thiele, 1995); furthermore, mutation and elitism are added (for details, the reader is referred to Whitley, 1994). The number of clusters in the GK algorithm must be chosen a priori; in order to avoid subjective choices, the following method is applied to the protoclusters. A Tmode Principal Component Analysis (PCA; Compagnucci and Richman, 2008) is run on the protoclusters, then a test of dimensionality is performed (Dray, 2008). Let $\mathbf{X}$ denote the observation $\mathrm{n}_{\mathrm{p}}$-matrix, PCA can be achieved with a Singular Value Decomposition of $\mathbf{X}$, i.e., $(1 / \sqrt{n}) \mathbf{X}=\mathbf{U D V}^{t}$, which is associated with the approximation of $\mathbf{X}$ by $\sum_{i=1}^{m} d_{i} \boldsymbol{u}_{i} \boldsymbol{v}_{i}^{t}=$ $\sum_{i=1}^{m} \mathbf{X}_{i}$. Therefore, as explained by Dray (2008), the test of PCA dimensionality becomes a test on the approximation of $\mathbf{X}$, i.e., on the relevance of information carried by the addition of $\mathbf{X}_{m+1}$ on $\left\{\mathbf{X}_{i}\right\}_{i=1, \ldots, m}$. This test can be performed 
Table 2. Estimated trend in the seasonal precipitation series. Only the significant $(\geq 90 \%)$ values and associated uncertainties are reported. The significance is derived with the Mann-Kendall test (Yue et al., 2002).

\begin{tabular}{ll}
\hline Station & Trend (mm/year) and std err \\
\hline Alexandroupoli & $-2.3 \pm 1.17$ \\
Amiantos & $-4.8 \pm 1.89$ \\
Argostoli & $-8.4 \pm 1.97$ \\
Cagliari & $-1.3 \pm 0.78$ \\
Marseille & $-2.1 \pm 1.1$ \\
Mytilene & $-2.8 \pm 1.58$ \\
Rhodes & $-5.8 \pm 1.92$ \\
Teramo & $-2.5 \pm 0.78$ \\
\hline
\end{tabular}

using a similarity measure (RV coefficient; Robert and Escoufier, 1976) between matrices, in fact, if $\mathbf{X}_{m+1}$ is relevant in terms of the approximation, then it should be close (in terms of similarity) to the residuals $\mathbf{R}_{m}$ of the approximation done with $m$ matrices. A complete description can be found in Appendix B. The proposed classification procedure avoids the trap of local solutions that led to the development of alternative methods to the classical k-means (e.g., SANDRA; Philipp et al., 2007); in addition, it is able to estimate (in an objective way) the optimal number of clusters.

Finally, the significance of the identified atmospheric anomaly patterns related to extreme daily precipitation is checked by the comparison with patterns during dry days and rainy days below the threshold (i.e., non-extreme wet days). The comparisons are done in the more general context of stochastic equality; i.e., $H_{0}: P(X<Y)=P(X>Y)$ against $P(X<Y) \neq P(X>Y)$ (e.g., Reiczigel et al., 2005). The nonparametric Brunner-Munzel test is performed for this task (Brunner and Munzel, 2000).

\section{Results and discussion}

Twelve out of 20 stations do not show a significant (less than 90\%) trend in the seasonal total precipitation series. Eight series are affected by an overall significant negative trend (Amiantos, Alexandroupoli, Argostoli, Mytilene, Rhodes, Marseille, Cagliari, Teramo; see Table 2). The series of Argostoli shows the highest decreasing trend $(-8.4 \pm 1.97 \mathrm{~mm} /$ year$)$, while the weakest significant trend is estimated for the series of Cagliari $(-1.3 \pm 0.78 \mathrm{~mm} /$ year; Table 2). It is important to outline that the absence of a significant trend in the seasonal series does not imply a similar behaviour for monthly series. For instance, in Spain, del Río et al. (2010) reported that $61 \%$ of the whole territory is affected by a decreasing precipitation trend in February. Since the focus of this paper is the characterisation of extreme precipitation in the extended winter season, we do not address this issue.
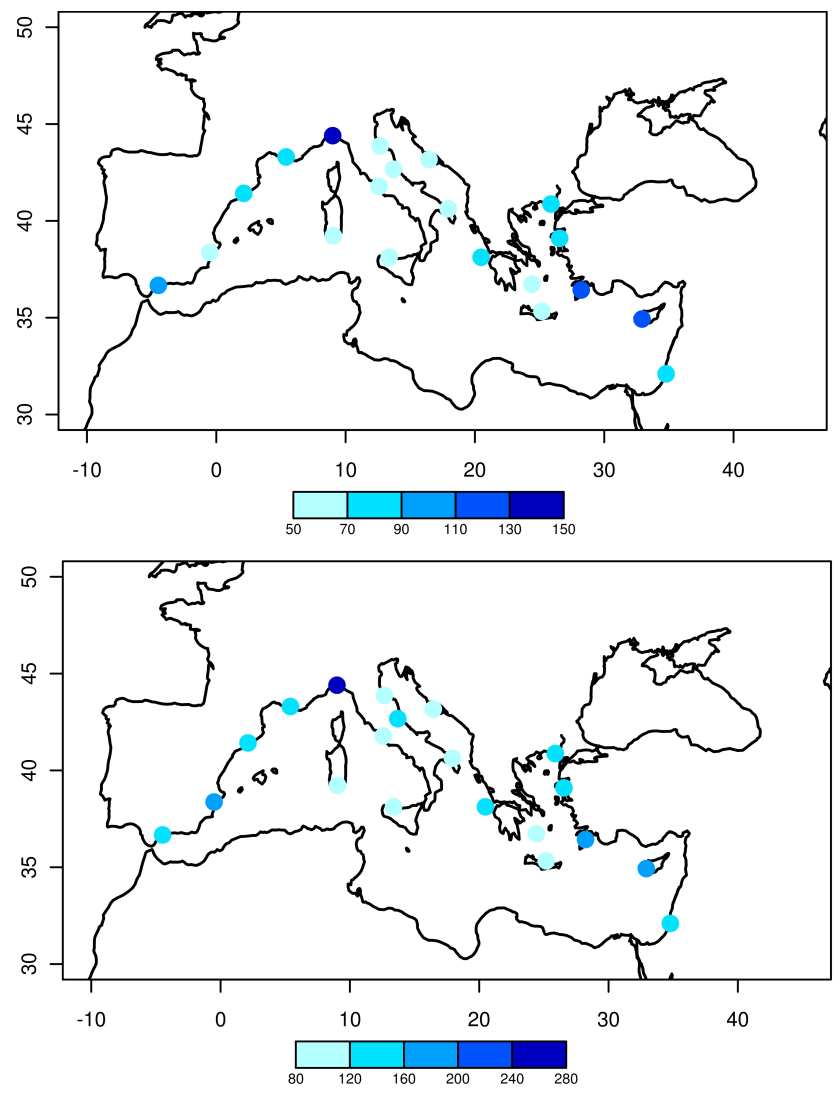

Fig. 2. Estimated 5-year (upper panel) and 50-year (bottom panel) return levels of each series. Values in $\mathrm{mm}$.

The application of the dePOT model to the selected series provides the estimated parameters shown in Fig. 1. Except for Mytilene and Rome, all the series have a positive shape parameter. The highest value is found for Alicante (Spain) and the lowest (among the positive values) for the series of Argostoli (Fig. 1). The heavy tailed behaviour of the series of Alicante confirms the high flood risk of the site (ESPONINTERACT, 2006). The expected high scale parameters of Genoa and Amiantos, located in the areas of the Genoa and Cyprus low pressure systems, can be easily identified in Fig. 1. Moreover, using the thresholds estimated with dePOT (see Sect. 3), the mean percentage of the total extended winter season precipitation due to events above the threshold is calculated. All the stations have a mean percentage of around $60 \%$ (e.g., Hvar-Croatia has a mean value equal to $60.4 \%$ ); therefore, it is evident that the events above the thresholds provide an important contribution to seasonal total precipitation. The return levels help in understanding and quantifying the behaviour of the most severe events. For this purpose, 5year and 50-year return levels are calculated (Fig. 2 and Table 1). The high values of Genoa, Rhodes and Amiantos are visible in both maps of Fig. 2 and for the 5-year period are approximately $150 \pm 22 \mathrm{~mm}, 114 \pm 16 \mathrm{~mm}$ and $115 \pm 13 \mathrm{~mm}$, 

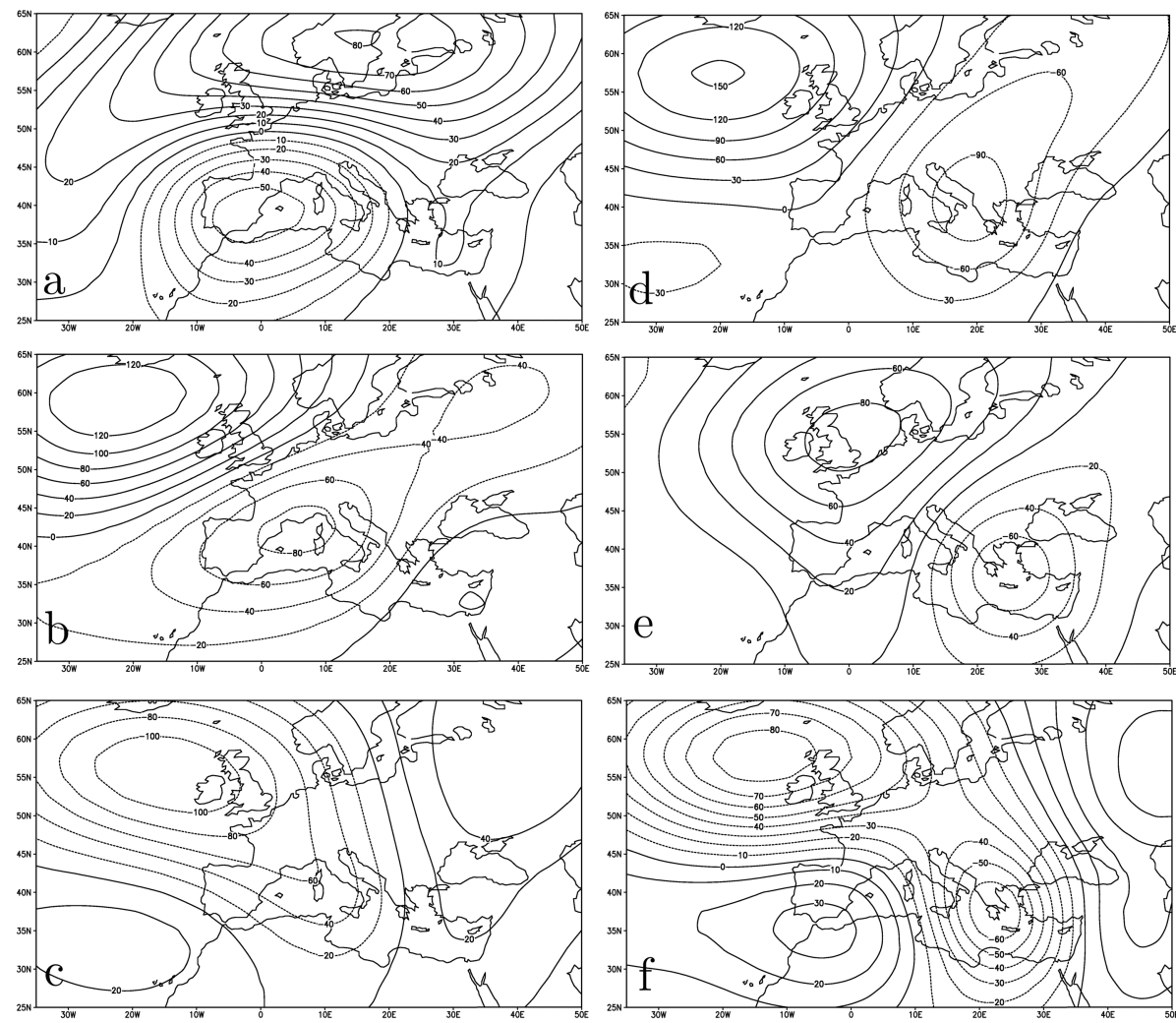

Fig. 3. Identified patterns of Z500 anomalies associated with extreme precipitation. The left panel refers to the western Mediterranean, while the right panel refers to the eastern Mediterranean.

respectively (Fig. 2 and Table 1). In order to investigate possible departures from stationarity of the Poisson component in the dePOT model, the series of exceedances are used to calculate the number of occurrences for each extended winter. Then, a Poisson regression (Cameron and Trivedi, 2001) is applied and only for six series (Amiantos, Cyprus; Marseille, France; Rhodes and Argostoli, Greece; Genoa and Teramo, Italy) a significant negative tendency is found. This indicates that the probability of observing an event above the threshold (at those six stations) has decreased over the last 57 years. Moreover, the estimated return levels of those series are a function of time and the values shown in Fig. 2 can be considered as mean return levels (since the occurrence rate of threshold exceedances is assumed to be stationary in the dePOT approach). Those tendencies might be related to the decrease of the most intense Mediterranean cyclones (Trigo et al., 2000; Bartholy et al., 2009).

The classification of atmospheric fields (Z500 and SLP) associated with extreme precipitation events (dry days and non-extreme wet days, for testing the significance as explained in the previous section) is performed for each station. Western and eastern Mediterranean anomaly patterns are derived classifying the station-centroids. For both Z500 and SLP, three clusters are found in the western Mediterranean (hereafter WM) and eastern Mediterranean (EM).
Figures 3 and 4 show the centroids of those clusters and highlight differences in the identified patterns. Regarding WM, a Z500 dipole structure characterises two out of three clusters, with an axis oriented South-West/North-East and South-East/North-West, respectively. In the first case, the negative and the positive anomalous centres are located between Spain and northwestern Africa (Fig. 3a) and over the Scandinavian Peninsula (with a wide extension towards north-eastern Europe), respectively. This favours anomalous mid-tropospheric southwesterly flow towards the WM. The SLP dipole (Fig. 4a) presents a similar structure with the axis shifted eastward. The second dipole structure of Z500 (Fig. 3b) shows a negative centre over the Gulf of Lion and the Balearic Sea, and a positive centre over the northern North Atlantic. As in the previous case, it also has a nearly barotropic structure (Fig. 4b), favouring an anomalous westerly-southwesterly flow to the WM. The third cluster (Fig. 3c) influencing the WM has a triple-centre structure, with a mid-tropospheric trough extending from the British Isles towards northern Africa (Algeria) and two anomalous positive centres in the subtropical North Atlantic and across north-eastern Europe. All the three clusters are associated with intensified moisture transport from the Atlantic (Trigo et al., 2006). Regarding EM, an anomalous mid-tropospheric trough stretching from the Baltic region to 

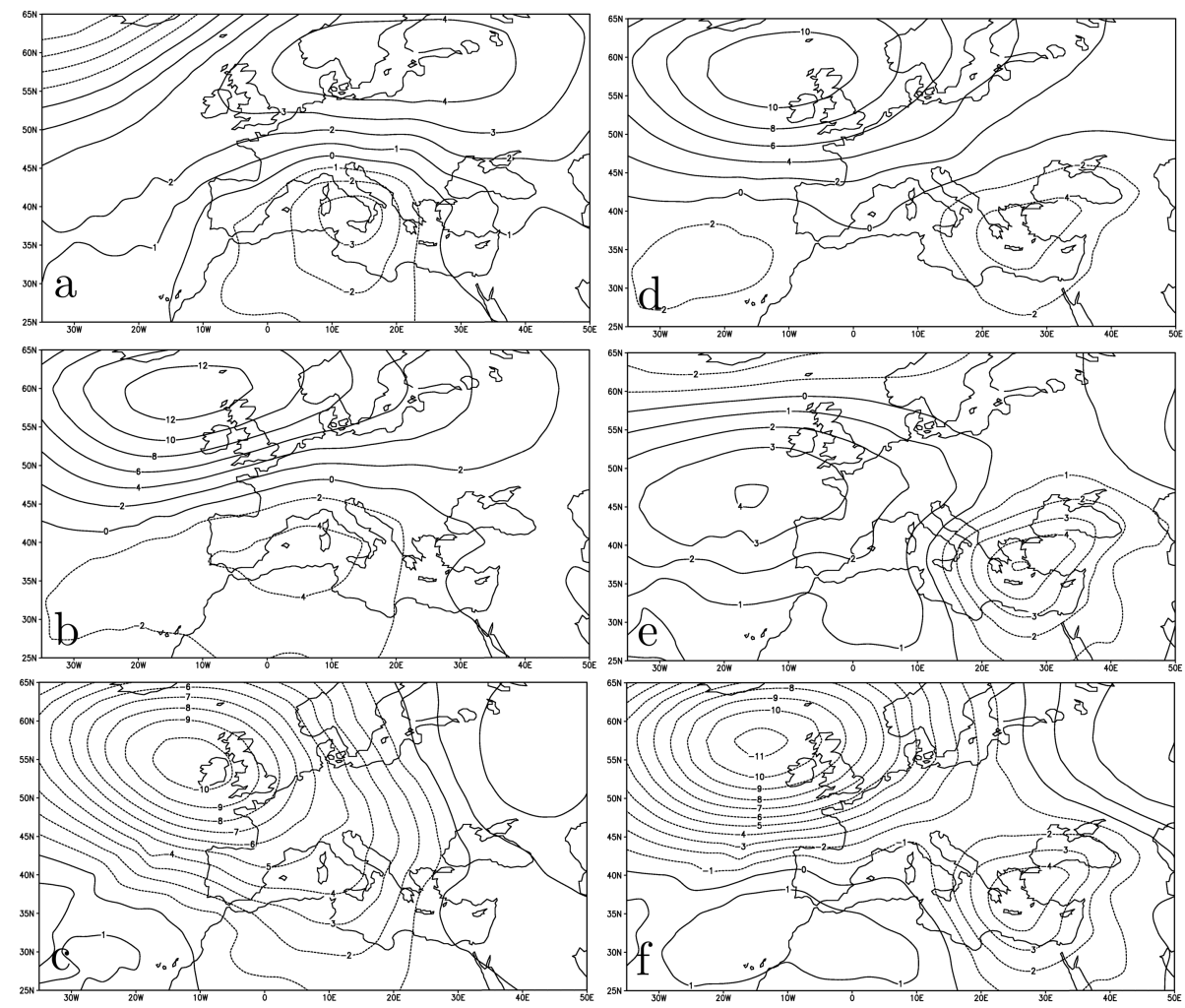

Fig. 4. As Fig. 3 but for SLP.

northeastern Africa (with positive Z500 anomalies over the North Atlantic) characterises the centroid of Fig. 3d. Moreover, the SLP (Fig. 4d) mimics a wide Cyprus low located over the eastern Mediterranean. The second pattern (Figs. 3e and 4 e) shows a negative anomalous centre located over the Aegean Sea and an anomalous positive area centred over the North Sea, with a strong southward extension towards the WM. Finally, the third centroid (Figs. $3 \mathrm{f}$ and $4 \mathrm{f}$ for SLP) has two centres of anomalous Z500, over Greece and between the British Isles and Iceland. Moreover, two anomalous positive areas extend from the Atlantic towards Italy and from Eastern Europe towards the Black Sea (Fig. 3f).

In order to validate the identified atmospheric patterns, Z500 and SLP anomalies are also classified with SANDRA (Philipp et al., 2007). The identified SANDRA-patterns (not shown) are similar to those obtained with our procedure. Finally, the significance of Z500/SLP patterns associated with extreme events for each station is tested through a comparison with the clusters associated with dry days and nonextreme wet days. Figure 5 shows the significance (grey areas) of western Mediterranean Z500 extreme-day clusters compared to dry-day clusters. In all the three cases, the strongest anomalous areas correspond to the grey areas, i.e., anomalies during extreme precipitation events are significantly different from the clusters of anomalies associated with dry days. Figure 6 presents the extreme-day centroids tested against the atmospheric anomalous patterns during non-extreme wet days. Also in this case, anomalies of Z500 associated with extreme daily precipitation are significant. Most of the regions have significant anomalies in both cases (i.e., extreme days against dry days and extreme days against non-extreme wet days) and the same holds for eastern Mediterranean and SLP patterns.

All the three anomaly Z500 EM-patterns agree with the rainfall mechanisms proposed by Eshel and Farrell (2000) and $\mathrm{Ziv}$ et al. (2010). On the right side of an anomalous low centre (in an equivalent barotropic context), southwesterly winds bring warm air towards the EM, causing vertical motion anomalies. This anomalous ascent affects the lower tropospheric moisture budget and contributes to anomalous rainfall (Eshel and Farrell, 2000). Moreover, non-significant correlation between precipitation and moisture flux divergence (Jin and Zangvil, 2009) enhances the important role of vertical moisture fluxes from the warm Mediterranean Sea combined with the moisture transport from the western part of the Basin (e.g., Trigo et al., 2006). The role of the Mediterranean Sea is also evident in the Conveyor Belt Model of Ziv et al. (2010) for the Mediterranean cyclones, where the warm belt plays a minor role (as a source of moisture) in contrast to its role in extratropical cyclones.

The events with daily precipitation $\geq 5$-year return levels are selected. For each station, composites of wind components at the $250 \mathrm{hPa}$ geopotential height level are calculated, in order to study the jet stream connected with $\geq 5$-year return 

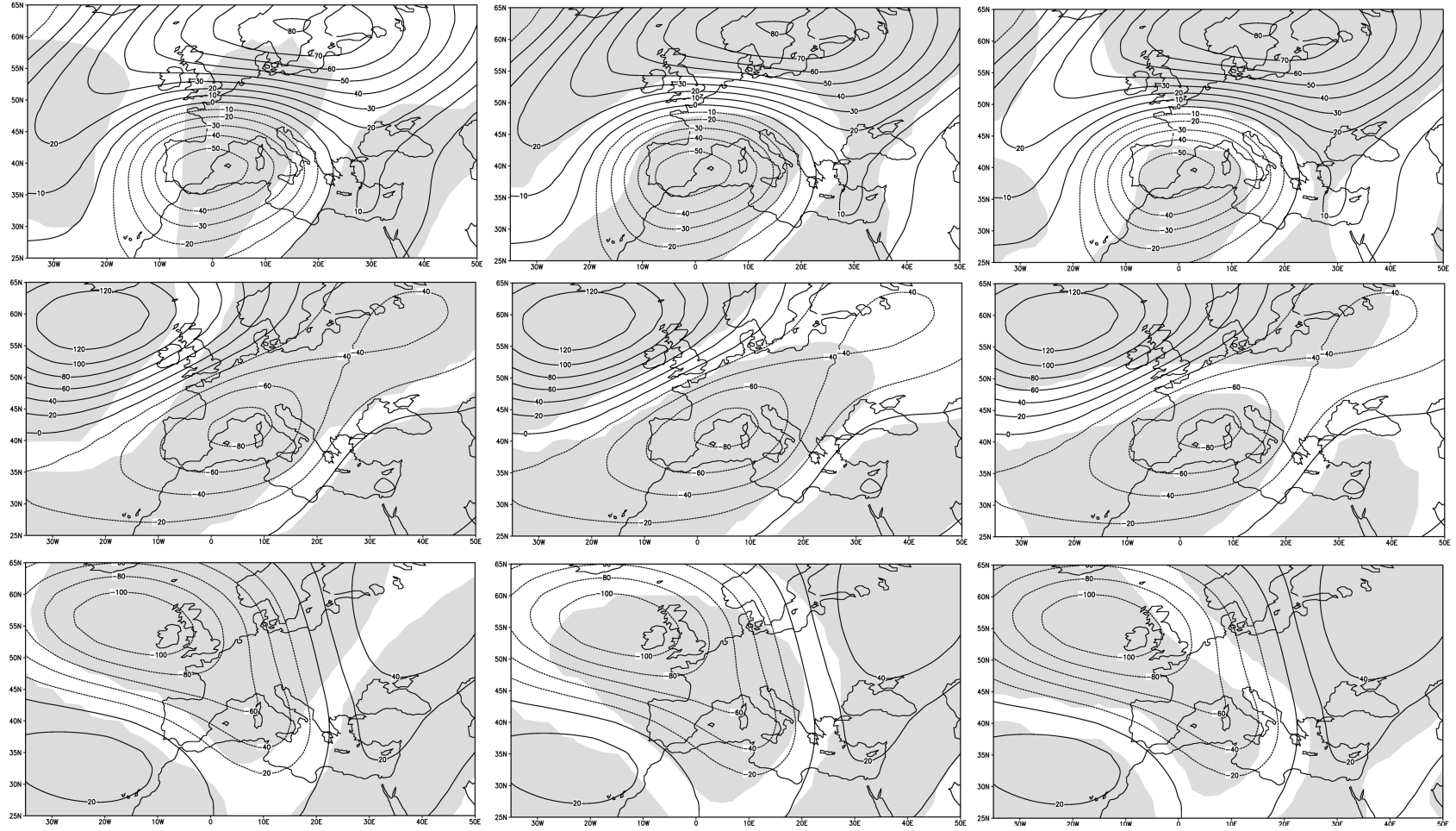

Fig. 5. Results of the Brunner-Munzel test applied to the three western Mediterranean Z500 clusters (one per row) during extreme precipitation days against Z500 clusters associated with dry days. Contour lines represent the centroids associated with extreme precipitation. The grey shadow denotes areas with significance $\geq 95 \%$.
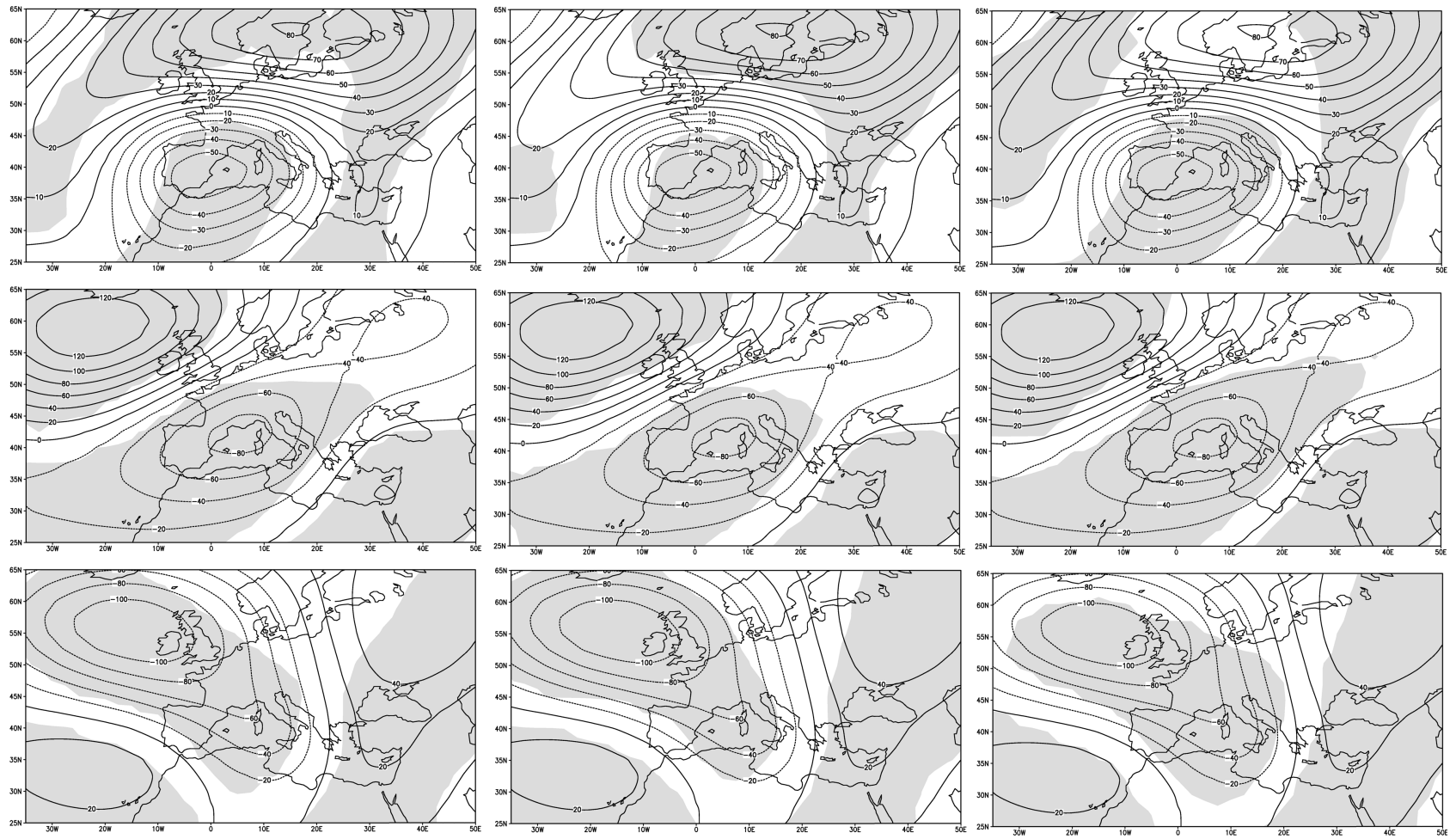

Fig. 6. Results of the Brunner-Munzel test applied to the three western Mediterranean Z500 clusters (one per row) during extreme precipitation days against Z500 clusters associated with non-extreme wet days. Contour lines represent the centroids associated with extreme precipitation. The grey shadow denotes areas with significance $\geq 95 \%$. 


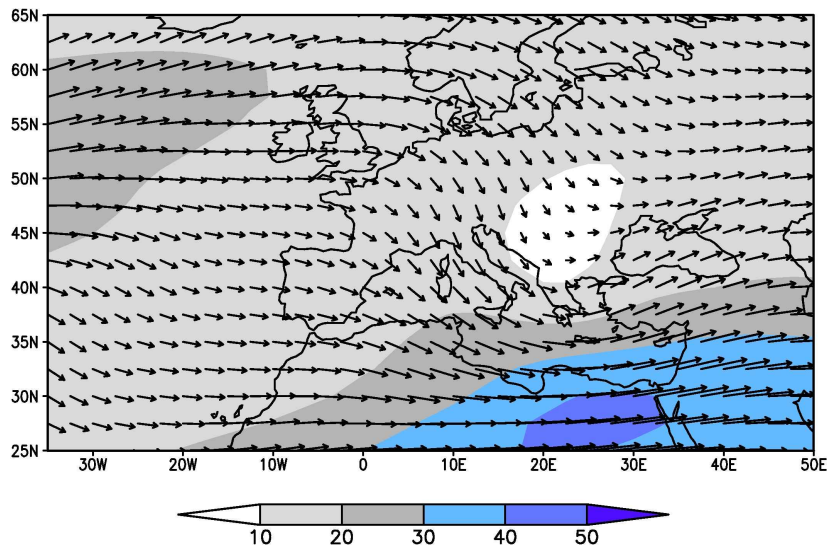

Fig. 7. Composite of wind at $250 \mathrm{hPa}$ for the eastern Mediterranean. Values are in $\mathrm{m} / \mathrm{s}$.

level events. Three common spatial configurations are identified for the whole Mediterranean; two affect the WM and one is related with the EM precipitation events. With regard to the EM, Fig. 7 shows the subtropical jet, with its axis oriented South-West/North-East and a streak located over Egypt. The position of the streak implies that the eastern Basin is on the left side of the exit region, i.e., on the divergence area (that is a key factor of cyclogenesis; Barry and Carleton, 2001). As for the WM, Fig. 8 highlights a first configuration, affecting the southern stations of WM, with the subtropical jet stream characterised by an axis parallel to the African coastline. In the second case, the interaction between the polar jet stream (or eddy driven jet stream) with the subtropical jet is evident and implies that the WM is on a strong divergence region; a similar mechanism was also found in the case of cyclogenesis over north-western Africa (Prezerakos et al., 2006).

\section{Conclusions}

An extreme value procedure, based on the Generalized Pareto Distribution and recently developed techniques (on the parameter estimations, the declustering scheme and the selection of the threshold), has been implemented. Then, it has been applied to 20 daily extended winter precipitation series collected from the Mediterranean area and covering the period 1950-2006. In comparison to index based approaches (e.g. number of days with daily precipitation greater than the 90th percentile), our results are more robust and include confidence intervals. Furthermore, our approach provides insight into extremal behaviour such as estimates of the shape parameter and high return levels. All of the series, except for Rome and Mytilene, have a heavy tailed behaviour, characterised by a positive shape parameter $\leq 0.4$. The estimated 5 -year return levels are between 58 and $150 \mathrm{~mm}$, with the highest value of the Genoa series. Regarding the 50-year return levels, the values range from $82 \mathrm{~mm}$ (Rome) to $264 \mathrm{~mm}$
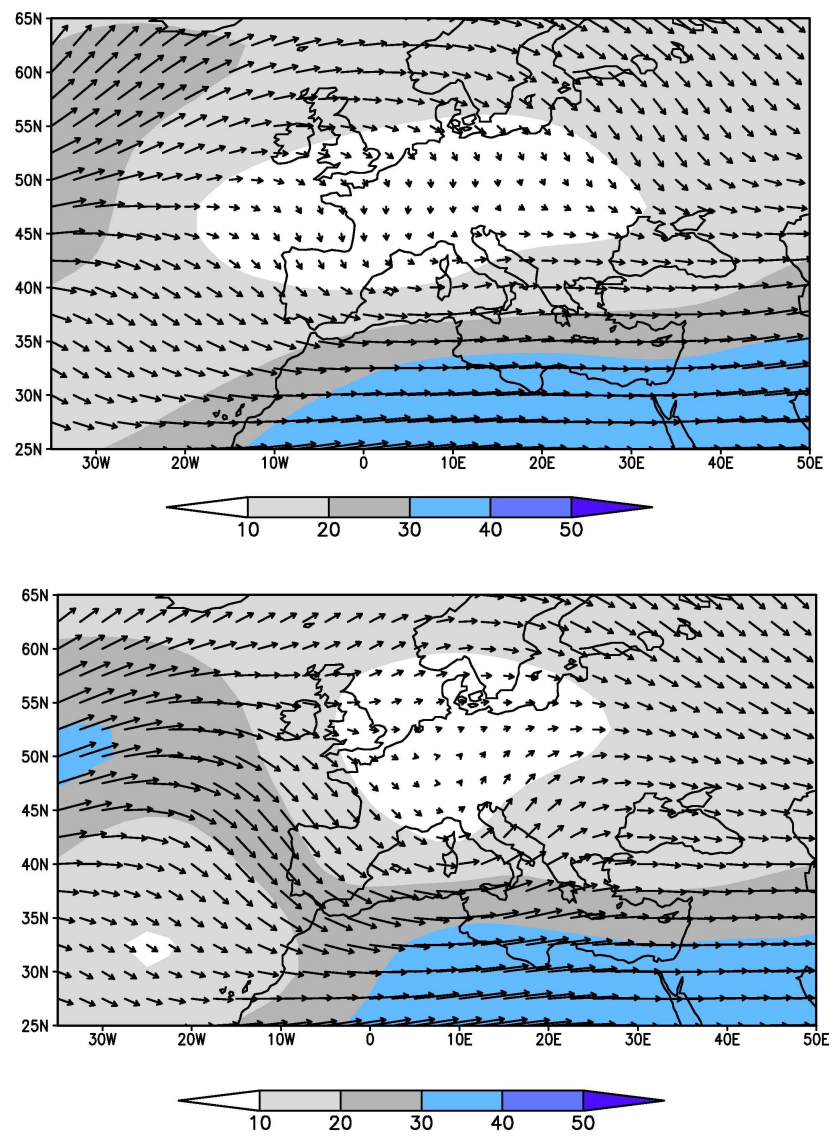

Fig. 8. Composites of wind at $250 \mathrm{hPa}$ for stations located in the southern part of the western Mediterranean (upper panel) and in other areas of the western basin (lower panel). Intensity of the wind is in $\mathrm{m} / \mathrm{s}$.

(Genoa). Moreover, it is interesting to point out the high 50 -year return level $(200 \pm 127 \mathrm{~mm})$ of the Alicante series, caused by the high positive shape parameter. Although the associated uncertainty is quite high, this result highlights the risks linked to extreme daily precipitation events. Most of the series do not show significant changes in the probability of events above threshold (i.e., extreme events), only for six series a decreasing trend has been identified. Finally, it is worth outlining that extreme daily precipitation events in the Mediterranean coastal sites provide a relevant contribution to seasonal totals (approximately 60\%).

A characterisation of the atmospheric patterns associated with extreme precipitation events has been performed by using a 2-step algorithm. As for Z500 and SLP, three main clusters have been found both for the western and eastern basin. These configurations of anomalies are significantly different from the clusters associated with dry days and nonextreme wet days. The identified patterns help us to understand the mechanisms of extreme precipitation events and to match physical explanations provided, especially for the 
eastern Mediterranean. The analysis of the jet stream during $\geq 5$-year return level events reveals three configurations; one for the EM and two for the WM. In all cases, the divergence side of the jet stream coincides with the area of interest and supports enhanced ascending motions. In the WM, the interaction of the subtropical and polar jet streams strengthens these features.

The proposed combination of an extreme statistical model and a procedure for the identification of atmospheric patterns can also be applied to other regions of the world or to other variables, for example, temperature. Both procedures can also be applied separately for resolving specific issues, for example, classification of atmospheric patterns not related with extremes. Regarding extreme models, some improvements can be done for climatic purposes. In fact, departures from stationarity (e.g., in the Poisson process), or covariate dependence, could be taken into account directly in the model. Consequently, the classical concept of a return level should be revised, because it becomes a function of time (e.g., Luterbacher et al., 2004). However, we believe that this study represents a first step towards a better description of the Mediterranean extremes and the physical mechanisms.

Finally, the proposed approach can also be applied to an ensemble of models with a focus on the Mediterranean basin. The Mediterranean area is considered a "hot-spot" of climate change (Giorgi, 2006) that is expected to suffer more dryness and heavy precipitation events in the future, although the response of these extremes acts over a long time period compared to mean precipitation and temperature (Goubanova and $\mathrm{Li}$, 2007). Therefore, an application of the extreme model can help to reveal and better characterise such features. An analysis of extremes, carried out on observed time series and model output, will provide robust results for deriving potential impacts and the management of climate risks.

\section{Appendix A}

Following Juárez and Schucany (2004), the MDPDE is based on density power divergence between two densities $f$ and $g$ belonging to an identifiable parametric family:

$$
\begin{aligned}
d_{\alpha}(g, f) & =\int\left\{f^{1+\alpha}(x)-\left(1+\alpha^{-1}\right) g(x) f^{\alpha}(x)\right. \\
& \left.+\alpha^{-1} g^{1+\alpha}(x)\right\} d x,
\end{aligned}
$$

where $\alpha$ is a control parameter. When $\alpha$ is equal to zero MDPDE is equivalent to the maximum likelihood estimator. Considering the GPD family, $k_{0}$ and $\sigma_{0}$ denote the opposite of the shape parameter (i.e., $k=-\xi$ ) and the scale parameter of the family, respectively. The MDPDE estimation $\left(\hat{k}_{\alpha}, \hat{\sigma}_{\alpha}\right)$ minimizes $d_{\alpha}\left(g, f\left(\cdot, k_{0}, \sigma_{0}\right)\right)$, i.e.

$$
\begin{aligned}
& H_{\alpha}(k, \sigma) \\
& =\left\{\sigma^{\alpha}(1+\alpha-\alpha k)\right\}^{-1} \\
& -\left(1+\alpha^{-1}\right) n^{-1} \sum_{i=1}^{n} \sigma^{-\alpha}\left(1-k X_{i} \sigma^{-1}\right)^{\left(k^{-1}-1\right) \alpha},
\end{aligned}
$$

where $X_{i}$ is the sample and $n$ is its length and with some restrictions on $(k, \sigma)$. Moreover, a consistent estimator of the variance-covariance matrix $\mathbf{V}$ is given by $n^{-1} \hat{\mathbf{J}}_{\alpha}^{-1} \hat{\mathbf{K}}_{\alpha} \hat{\mathbf{J}}_{\alpha}^{-1}$, where $\mathbf{J}_{\alpha}$ and $\mathbf{K}_{\alpha}$ depend on the information (i) and the score (S) matrix (obtained using the estimated parameters):

$$
\begin{aligned}
\mathbf{J}_{\alpha} & =(1+\alpha) \int_{D} \mathbf{S S}^{t} f^{\alpha+1} d x-\int_{D} \mathbf{i} f^{\alpha+1} d x \\
& +n^{-1} \sum_{i=1}^{n}\left\{\mathbf{i}-\alpha \mathbf{S S}^{t}\right\} f^{\alpha} \\
\mathbf{K}_{\alpha} & =n^{-1} \sum_{i=1}^{n} \mathbf{S S}^{t} f^{2 \alpha}-n^{-2}\left\{\sum_{i=1}^{n} \mathbf{S} f^{\alpha}\right\}\left\{\sum_{i=1}^{n} \mathbf{S} f^{\alpha}\right\}^{t} .
\end{aligned}
$$

The integration interval $D$ is equal to $[0, \infty)$ when the shape is greater or equal to zero and it is $\left[0, \sigma k^{-1}\right]$ when the shape is negative. For further details refer to Juárez and Schucany (2004).

\section{Appendix B}

The statistic associated with the similarity measure of $\mathbf{X}_{m+1}$ and $\mathbf{R}_{m}$ is:

$$
\begin{aligned}
& \operatorname{RVDIM}(m)=\operatorname{RV}\left(\mathbf{X}_{m+1}, \mathbf{R}_{m}\right) \\
& =\frac{\operatorname{tr}\left(\mathbf{X}_{m+1}^{t} \mathbf{R}_{m} \mathbf{R}_{m}^{t} \mathbf{X}_{m+1}\right)}{\sqrt{\operatorname{tr}\left(\mathbf{X}_{m+1}^{t} \mathbf{X}_{m+1} \mathbf{X}_{m+1}^{t} \mathbf{X}_{m+1}\right) \operatorname{tr}\left(\mathbf{R}_{m}^{t} \mathbf{R}_{m} \mathbf{R}_{m}^{t} \mathbf{R}_{m}\right)}}
\end{aligned}
$$

Following Dray (2008), the testing procedure can be implemented in this way:

\section{SVD of $\mathbf{X}$.}

2. Computation of the RVDIM statistic.

3. Iteration of:

- Randomization of $\mathbf{X}$ columns.

- SVD of $\mathbf{X}$.

- Computation of RVDIM.

4. Estimation of the p-values, $p_{m}$, associated with the mcomponent.

5. Fixed a significance level $\alpha$, the number of significant components $k$ is such that $p_{k}<\alpha$ and $p_{k+1}>\alpha$. 
Acknowledgements. We acknowledge Sergio F. Juárez for his S-plus routine and helpful discussions. We thank Walter Perconti and Guido Fioravanti (ISPRA) for useful discussions on SOM and Valentina Pavan (ARPA-EMR) for providing data from Emilia-Romagna. We thank Nico Hofmann and Martina Hartwig for digitalization of the Teramo station series and Valter Varani for providing the last years of Teramo daily data. We are grateful to G. van der Schrier and partners from the European Climate Assessment and Data set (ECA\&D) at the KNMI, the Hellenic National Meteorological Service, O. M. Gokturk and the Turkish State Meteorological Service for providing data. This research was funded by the EU/FP6 integrated project CIRCE (Climate Change and Impact Research: the Mediterranean Environment; http://www.circeproject.eu/; contract number 036961). Jürg Luterbacher acknowledges support from the EU/FP7 project ACQWA (Assessing Climate Impacts on the Quantity and Quality of Water; http://www.acqwa.ch/; grant 212250) and MedClivar (http://www.medclivar.eu/). We thank two anonymous reviewers for their useful comments. The procedures described in Sect. 2 are fully developed in R (www.r-project.org).

Edited by: R. García-Herrera

Reviewed by: two anonymous referees

\section{References}

Alpert, P., Ben-Gai, T., Baharad, A., Benjamini, Y., Yekutieli, D., Colacino, M., Diodato, L., Ramis, C., Homar, V., Romero, R., Michaelides, S., and Manes, A.: The paradoxical increase of Mediterranean extreme daily rainfall in spite of decrease in total values, Geophys. Res. Lett., 29, 1536, doi:10.1029/2001GL013554, 2002.

Barry, R. G. and Carleton, A. M.: Synoptic and Dynamic Climatology, Routledge, London, 2001.

Bartholy, J., Pongrácz, R., and Pattantyús-Ábrahám, M.: Analyzing the genesis, intensity, and tracks of western Mediterranean cyclones, Theor. Appl. Climatol., 96, 133-144, 2009.

Blickle, T. and Thiele, L.: A mathematical analysis of tournament selection, Proc. of the 6th Intern. Conf. on Genetic Algorithms, Morgan Kaufmann Publishers, San Francisco, 9-16, 1995.

Brunet, M., Sigró, J., Jones, P. D., Saladié, O., Aguilar, E., Moberg, A., Lister, D., and Walther, A.: Long-term changes in extreme temperatures and precipitation in Spain, Contribution to Science, 3, 331-342, 2007.

Brunetti, M., Maugeri, M., Nanni, T., Auer, I., Böhm, R., and Schöner, W.: Precipitation variability and changes in the Greater Alpine region over the 1800-2003 period, J. Geophys. Res., 111, D11107, doi:10.1029/2005JD006674, 2006.

Brunner, E. and Munzel, U.: The nonparametric Behrens-Fisher problem: asymptotic theory and a small sample approximation, Biometrical J., 42, 17-25, 2000.

Cameron, A. C. and Trivedi, P. K.: Essentials of count data regression, in: A companion to theoretical econometrics, edited by: Baltagi, B. H., Blackwell, Oxford, 331-348, 2001.

Castillo, E. and Hadi, A. S.: Fitting the Generalized Pareto Distribution, J. Am. Stat. Assoc., 92, 1609-1620, 1997.

Caussinus, H. and Mestre, O.: Detection and correction of artificial shifts in climate series, Appl. Stat.-J. Roy. St. C, 53, 405-425, 2004.
Choulakian, V. and Stephens, M. A.: Goodness-of-fit for the Generalized Pareto Distribution, Technometrics, 43, 478-484, 2001.

Coles, S.: An Introduction to Statistical Modeling of Extreme Values, Springer-Verlag, London, 2001.

Coles, S. and Pericchi, L.: Anticipating catastrophes through extreme value modelling, Appl. Stat.-J. Roy. St. C, 52, 405-416, 2003.

Compagnucci, R. H. and Richman, M. B.: Can principal component analysis provide atmospheric circulation or teleconnection patterns?, Int. J. Climatol., 28, 703-726, 2008.

Corte-Real, J., Zhang, X., and Wang, X.: Large-scale circulation regimes and surface climatic anomalies over the Mediterranean, Int. J. Climatol., 15, 1135-1150, 1995.

Costa, A. C. and Soares, A.: Trends in extreme precipitation indices derived from a daily rainfall database for the South of Portugal, Int. J. Climatol., 29, 1956-1975, 2009.

Davison, A. C. and Smith, R. L.: Models for Exceedances over High Thresholds, J. Roy. Stat. Soc. B Met., 52, 393-442, 1990.

De Luis, M., González-Hidalgo, J. C., Longares, L. A., and Stepánek, P.: Seasonal precipitation trends in the Mediterranean Iberian Peninsula in second half of the 20th century, Int. J. Climatol., 29, 1312-1323, 2009.

del Río, S., Herrero, L., Fraile, R., and Penas, A.: Spatial distribution of recent rainfall trends in Spain (1961-2006), Int. J. Climatol., doi:10.1002/joc.2111, in press, 2010.

Dray, S.: On the number of principal components: a test of dimensionality based on measurements of similarity between matrices, Comput. Stat. Data An., 52, 2228-2237, 2008.

Dünkeloh, A. and Jacobeit, J.: Circulation dynamics of Mediterranean precipitation variability 1948-98, Int. J. Climatol., 23, 1843-1866, 2003.

EEA: Urban sprawl in Europe, EEA report No. 10, 2006.

Eisele, H., Scheel, H. E., Sladkovic, R., and Trickl, T.: Highresolution Lidar measurements of stratosphere-troposphere exchange, J. Atmos. Sci., 56, 319-330, 1999.

EM-DAT: The OFDA/CRED International Disaster Database, www.emdat.net, Université catholique de Louvain, Brussels, 2009.

Eshel, G. and Farrell, B. F.: Mechanisms of Eastern Mediterranean rainfall variability, J. Climate, 57, 3219-3232, 2000.

ESPON: Territorial trends and policy impacts in the field of EU environmental policy, ESPON 2.4.1, edited by: Klein, J. and Jarva, J., 2006.

ESPON-INTERACT: Environmental hazards and risk management-thematic study of Interreg and Espon activities, 2006.

Ferro, C. A. T. and Segers, J.: Inference for clusters of extreme values, J. Roy. Stat. Soc. B Met., 65, 545-556, 2003.

Foley, J. A., DeFries, R., Asner, G. P., Barford, C., Bonan, G., Carpenter, S. R., Chapin, F. S., Coe, M. T., Daily, G. C., Gibbs, H. K., Helkowski, J. H., Holloway, T., Howard, E. A., Kucharik, C. J., Monfreda, C., Patz, J. A., Prentice, C. I., Ramankutty, N., and Snyder, P. K.: Global consequences of land use, Science, 22, 570-574, 2005.

Frich, P., Alexander, L. V., Della-Marta, P. M., Gleason, B., Haylock, M., Klein Tank, A. M. G., and Peterson, T.: Observed coherent changes in climate extremes during the second half of the twentieth century, Clim. Res., 19, 193-212, 2002. 
Gallego, M. C., García, J. A., Vaquero, J. M., and Mateos, V. L.: Changes in frequency and intensity of daily precipitation over the Iberian Peninsula, J. Geophys. Res., 111, D24105, doi:10.1029/2006JD007280, 2006.

Giorgi, F.: Climate change hot-spots, Geophys. Res. Lett., 33, L08707, doi:10.1029/2006GL025734, 2006.

González-Hidalgo, J. C., De Luis, M., Raventós, J., and Sánchez, J. R.: Spatial distribution of seasonal rainfall trends in a western Mediterranean area, Int. J. Climatol., 21, 843-860, 2001.

Goubanova, K. and Li, L.: Extremes in temperature and precipitation around the Mediterranean basin in an ensemble of future climate scenario simulations, Global Planet. Change, 57, 27-42, 2007.

Hartigan, J. A. and Wong, M. A.: A K-means clustering algorithm, J. Roy. Stat. Soc. C-App., 28, 100-108, 1979.

Haylock, M. R. and Goodess, C. M.: Interannual variability of European extreme winter rainfall and links with mean large-scale circulation, Int. J. Climatol., 24, 759-776, 2004.

Holland, J. H.: Adaptation in natural and artificial systems, MIT Press, Cambridge, 1992.

Hosking, J. R. M. and Wallis, J. R.: Parameter and quantile estimation for the Generalized Pareto Distribution, Technometrics, 29, 339-349, 1987.

IPCC: Workshop on changes in extreme weather and climate events, Beijing, China, 11-13 June 2002.

Jin, F. and Zangvil, A.: Relationship between moisture budget components over the eastern Mediterranean, Int. J. Climatol., 30(5), 733-742, 2009.

Juárez, S. F. and Schucany, W. R.: Robust and efficient estimation for the Generalized Pareto Distribution, Extremes, 7, 237-251, 2004.

Kalnay, E., Kanamitsu, M., Kistler, R., Collins, W., Deaven, D., Gandin, L., Iredell, M., Saha, S., White, G., Woollen, J., Zhu, Y., Leetmaa, A., Reynolds, R., Chelliah, M., Ebisuzaki, W., Higgins, W., Janowiak, J., Mo, K.C., Ropelewski, C., Wang, J., Jenne, R., and Joseph, D.: The NCEP/NCAR 40-year reanalyis project, B. Am. Meteorol. Soc., 77, 437-470, 1996.

Keyser, D. and Shapiro, M. A.: A review of the structure and dynamics of upper-level frontal zones, Mon. Weather Rev., 114, 452-499, 1986.

Kioutsioukis, I., Melas, D., and Zerefos, C.: Statistical assessment of changes in climate extremes over Greece (1955-2002), Int. J. Climatol., doi:10.1002/joc.2030, in press, 2010.

Kistler, R., Kalnay, E., Collins, W., Saha, S., White, G., Woollen, J., Chelliah, M., Ebisuzaki, W., Kanamitsu, M., Kousky, V., van den Dool, H., Jenne, R., and Fiorino, M.: The NCEP/NCAR 50-year reanalyis: monthly means cd-rom and documentation, B. Am. Meteorol. Soc., 82, 247-267, 2001.

Klein Tank, A. M. G. and Können, G. P.: Trends in indices of daily temperature and precipitation extremes in Europe, 1946-99, J. Climate, 16, 3665-3680, 2003.

Kohonen, T.: Self-Organizing Maps, Springer-Verlag, Berlin, 2001.

Kostopoulou, E. and Jones, P. D.: Assessment of climate extremes in the Eastern Mediterranean, Meteorol. Atmos. Phys., 89, 69$85,2005$.

Krichak, S. O., Kishcha, P., and Alpert, P.: Decadal trends of main Eurasian oscillations and the Eastern Mediterranean precipitation, Theor. Appl. Climatol., 72, 209-220, 2002.
Krishna, K. and Narasimha Murty, M.: Genetic K-means algorithm, IEEE T. Syst. Man Cy. B, 29, 433-439, 1999.

Krivobokova, T. and Kauermann, G.: A note on Penalized spline smoothing with correlated errors, J. Am. Stat. Assoc., 102, 13281337, 2007.

Leadbetter, M. R., Lindgren, G., and Rootzén, H.: Extremes and related properties of random sequences and processes, SpringerVerlag, New York, 1983.

López-Moreno, J. I., Vicente-Serrano, S. M., Angulo-Martínex, M., Beguería, S., and Kenawy, A.: Trends in daily precipitation on the northeastern Iberian Peninsula, 1955-2006, Int. J. Climatol., doi:10.1002/joc.1945, in press, 2010.

Luterbacher, J., Dietrich, D., Xoplaki, E., Grosjean, M., and Wanner, H.: European seasonal and annual temperature variability, trends, and extremes since 1500, Science, 303, 1499-1503, 2004.

Maraun, D., Rust, H. W., and Osborn, T. J.: The annual cycle of heavy precipitation across the United Kingdom: a model based on extreme value statistics, Int. J. Climatol., 29, 1731-1744, 2009.

Maraun, D., Osborn, T. J., and Rust, H. W.: The influence of synoptic airflow on UK daily precipitation extremes. Part I: observed spatio-temporal relationships, Clim. Dynam., doi:10.1007/s00382-009-0710-9, in press, 2010a.

Maraun, D., Rust, H. W., and Osborn, T. J.: Synoptic airflow and UK daily precipitation extremes. Development and validation of a vector generalised linear model, Extremes, 13, 133-153, 2010b.

Moberg, A., Jones, P. D., Lister, D., Walther, A., Brunet, M., Jacobeit, J., Alexander, L. V., Della-Marta, P. M., Luterbacher, J., Yiou, P., Chen, D., Klein Tank, A. M. G., Saladié, O., Sigró, J., Aguilar, E., Alexandersson, H., Almarza, C., Auer, I., Barriendos, M., Begert, M., Bergström, H., Böhm, R., Butler, C. J., Caesar, J., Drebs, A., Founda, D., Gestengarbe, F. W., Micela, G., Maugeri, M., Österle, H., Pandzic, K., Petrakis, M., Srnec, L., Tolasz, R., Tuomenvirta, H., Werner, P. C., Linderholm, H., Philipp, A., Wanner, H., and Xoplaki, E.: Indices for daily temperature and precipitation extremes in Europe analysed for the period 1901-2000, J. Geophys. Res., 111, D22106, doi:10.1029/2006JD007103, 2006.

Norrant, C. and Douguédroit, A.: Monthly and daily precipitation trends in the Mediterranean (1950-2000), Theor. Appl. Climatol., 83, 89-106, 2006.

Pavan, V., Tomozeiu, R., Cacciamani, C., and Di Lorenzo, M.: Daily precipitation observations over Emilia-Romagna: mean values and extremes, Int. J. Climatol., 15, 2065-2079, 2008.

Peng, L. and Welsh, A.: Robust estimation of the Generalized Pareto Distribution, Extremes, 4, 53-65, 2002.

Philipp, A., Della-Marta, P. M., Jacobeit, J., Fereday, D. R., Jones, P. D., Moberg, A., and Wanner, H.: Long-term variability of daily North Atlantic-European pressure patterns since 1850 classified by simulated annealing clustering, J. Climate, 20, 4065-4095, 2007.

Pickands, J.: Statistical inference using extreme order statistics, Ann. Stat., 3, 119-131, 1975.

Prezerakos, N. G., Flocas, H. A., and Brikas, D.: The role of the interaction between polar and subtropical jets in a case of depression rejuvenation over the eastern Mediterranean, Meteorol. Atmos. Phys., 92, 139-151, 2006. 
Quadrelli, R., Pavan, V., and Molteni, F. : Wintertime variability of Mediterranean precipitation and its links with large-scale circulation anomalies, Clim. Dynam., 17, 457-466, 2001.

Reiczigel, J., Zakariás, I., and Rózsa, L.: A bootstrap test of stochastic equality of two populations, Am. Stat., 59, 1-6, 2005.

Robert, P. and Escoufier, Y.: A unifying tool for linear multivariate statistical methods: the RV coefficient, Appl. Statist., 25, 257265, 1976.

Rodrigo, F. S. and Trigo, R. M.: Trends in daily rainfall in the Iberian Peninsula from 1951 to 2002, Int. J. Climatol., 27, 513529, 2007.

Rust, H. W., Maraun, D., and Osborn, T. J.: Modelling seasonality in extreme precipitation. A UK case study, Eur. Phys. J.-Spec. Top., 174, 99-111, 2009.

Ruti, P. M., Lucarini, V., Dell'Aquila, A., Calmanti, S., and Speranza, A.: Does the subtropical jet catalyze the midlatitude atmospheric regimes?, Geophys. Res. Lett., 33, L06814, doi:10.1029/2005GL024620, 2006.

Shao, J.: Mathematical Statistics, Springer-Verlag, New York, 2003.

Shapiro, M. A.: Turbulent mixing within tropopause folds as a mechanism for the exchange of chemical constituents between the stratosphere and troposphere, J. Atmos. Sci., 37, 994-1004, 1980 .

Strong, C. and Davis, R. E.: Winter jet stream trends over the Northern Hemisphere, Q. J. Roy. Meteor. Soc., 133, 2109-2115, 2007.

Tolika, K., Anagnostopoulou, Chr., Maheras, P., and Kutiel, H.: Extreme precipitation related to circulation types for four case studies over the Eastern Mediterranean, Adv. Geosci., 12, 8793, 2007,

http://www.adv-geosci.net/12/87/2007/.

Toreti, A., Fioravanti, G., Perconti, W., and Desiato, F.: Annual and seasonal precipitation over Italy from 1961 to 2006, Int. J. Climatol., 29, 1976-1987, 2009.

Toreti, A., Kuglitsch, F. G., Xoplaki, E., and Luterbacher, J.: Time series segmentation: an approach based on a Genetic Algorithm and Hidden Markov Models, Nonlin. Processes Geophys., in review, 2010.

Trenberth, K. E., Jones, P. D., Ambenje, P., Bojariu, R., Easterling, D., Klein Tank, A., Parker, D., Rahimzadeh, F., Renwick, J. A., Rusticucci, M., Soden, B., and Zhai, P.: Observations: Surface and Atmospheric Climate Change, In: Climate Change 2007: The Physical Science Basis. Contribution of WG 1 to the Fourth Assessment Report of IPCC edited by: Solomon, S., Qin, D., Manning, M., Chen, Z., Marquis, M., Averyt, K. B., Tignor, M., and Miller, H. L., Cambridge University Press, UK and USA, 2007.

Trigo, I. F., Davies, T. D., and Bigg, G. R.: Decline in Mediterranean rainfall caused by weakening of Mediterranean cyclones, Geophys. Res. Lett., 27, 2913-2916, 2000.

Trigo, R., Xoplaki, E., Zorita, E., Luterbacher, J., Krichak, S. O., Alpert, P., Jacobeit, J., Sáenz, J., Fernández, J., GonzálezRouco, F., Garcia-Herrera, R., Rodo, X., Brunetti, M., Nanni, T., Maugeri, M., Türkes, M., Gimeno, L., Ribera, P., Brunet, M., Trigo, I. F., Crepon, M., and Mariotti, A. : Relations between variability in the Mediterranean region and mid-latitude variability, in: Mediterranean climate variability, edited by: Lionello, P., Rizzoli, P., and Boscolo, R., Elsevier, Amsterdam, 180-226, 2006.
Türkes, M.: Influence of geopotential heights, cyclone frequency and southern oscillation on rainfall variations in Turkey, Int. J. Climatol., 18, 649-680, 1998.

Türkes, M., Koc, T., and Saris, F.: Spatiotemporal variability of precipitation total series over Turkey, Int. J. Climatol., 29, 10561074, 2009.

Valero, F., Luna, M. Y., Martín, M. L, Morata, A., and GonzálezRouco, F.: Coupled modes of large-scale climatic variables and regional precipitation in the western Mediterranean in autumn, Clim. Dynam., 22, 307-323, 2004.

Vesanto, J. and Alhoniemi, E.: Clustering of Self-Organizing Map, IEEE T. Neural Networ., 11, 586-600, 2000.

Vrac, M. and Naveau, P.: Stochastic downscaling of precipitation: from dry events to heavy rainfalls, Water Resour. Res., 43, W07402, doi:10.1029/2006WR005308, 2007.

Whitle, D.: A Genetic Algorithm Tutorial, Stat. Comput., 4, 65-85, 1994.

Xoplaki, E.: Climate variability over the Mediterranean, Ph.D. thesis, University of Bern, Bern, available at: http://sinus.unibe.ch/ klimet/docs/phd_xoplaki.pdf(last access: 18 May 2010), 2002.

Xoplaki, E., González-Rouco, J. F., Luterbacher, J., and Wanner, H.: Wet season Mediterranean precipitation variability: influence of large-scale dynamics and trends, Clim. Dynam., 23, 63-78, 2004.

Yiou, P. and Nogaj, M.: Extreme climatic events and weather regimes over the North Atlantic: when and where?, Geophys. Res. Lett., 31, L07202, doi:10.1029/2003GL019119, 2004.

Yiou, P., Goubanova, K., Li, Z. X., and Nogaj, M.: Weather regime dependence of extreme value statistics for summer temperature and precipitation, Nonlin. Processes Geophys., 15, 365-378, 2008 , http://www.nonlin-processes-geophys.net/15/365/2008/.

Yue, S., Pilon, P., Phinney, B., and Cavadias, G.: The influence of autocorrelation on the ability to detect trend in hydrological series, Hydrol. Process., 16, 1807-1829, 2002.

Zhang, X., Aguilar, E., Sensoy, S., Melkonyan, H., Tagiyeva, U., Ahmed, N., Kutaladze, N., Rahimzadeh, F., Taghipour, A., Hantosh, T.H., Alpert, P., Semawi, M., Ali, M. K., Said Al-Shabibi, M. H., Al-Oulan, Z., Zatari, T., Al Dean Khelet, I., Hamoud, S., Sagir, R., Demircan, M., Eken, M., Adiguzel, M., Alexander, L., Peterson, T. C., and Wallis, T.: Trends in Middle East climate extreme indices from 1950 to 2003, J. Geophys. Res., 110, D22104, doi:10.1029/2005JD006181, 2005.

Ziv, B., Dayan, U., Kushnir, Y., Roth, C., and Enzel, Y.: Regional and global atmospheric patterns governing rainfall in the southern levant, Int. J. Climatol., 26, 55-73, 2006.

Ziv, B., Saaroni, H., Romen, M., Heifetz, E., Harnik, N., and Baharad, A.: Analysis of conveyor belts in winter Mediterranean cyclones, Theor. Appl. Climatol., 99, 441-455, 2010.

Zorita, E., Kharin, V., and von Storch, H.: The atmospheric circulation and sea surface temperature in the North Atlantic area in winter: their interaction and relevance for Iberian precipitation, J. Climate, 5, 1097-1108, 1992. 